\title{
SUBJETIVIDAD Y VIOLACIÓN SOCIAL. EL CASO DE LA MANADA
}

\author{
SUBJECTIVITY AND SOCIAL VIOLATION: \\ THE «LA MANADA» CASE
}

\section{María ANGULO EGEA \\ Universidad de Zaragoza mangulo@unizar.es}

Resumen: Este artículo analiza el discurso que los medios españoles han contribuido a construir y difundir sobre el denominado «Caso de La Manada». Se apuntan aquellas subjetividades que han emergido en la construcción narrativa de este caso vinculadas a la cultura de la violación que permea la sociedad y al ejercicio de lo que Nerea Barjola denomina microfisica sexista del poder. En concreto nos detenemos en el análisis del discurso que difundieron prensa escrita y televisión española principalmente, durante el mes de noviembre de 2017, cuando tuvo lugar el juicio oral por el denominado «Caso de La Manada» en la Audiencia Provincial de Navarra.

Palabras clave: «Caso La Manada», subjetividad, heteropatriarcado, victimización secundaria, abuso sexual, microfísica sexista.

\begin{abstract}
This article analyzes the discourse that the Spanish media has created and disseminated about the so-called «La Manada» sexual abuse case. The subjectivity that has emerged in the construction of the narrative of this case is linked to the culture of rape that permeates society and the exercise of what Nerea Barjola calls the sexist microphysics of power. Specifically, we focus on an analysis of Spanish printed press and television during the month of November 2017, when the oral trial took place in the Provincial Court of Navarra.
\end{abstract}

Keywords: «La Manada Case», subjectivity, heteropatriarchy, «secondary victimization», «sexual abuse», «sexist microphysics». 
Una violación no es nunca solo una violación por más que la víctima la viva lógicamente como $\ll$ única y absolutamente personal. Una violación, y el consiguiente juicio y tratamiento social son un reflejo de la historia de las relaciones entre hombres y mujeres y un reflejo social, simbólico, material, jurídico, mediático etc., de la posición de mujeres y hombres en una sociedad dada.» Estas palabras de Beatriz Gimeno en su artículo «¿A quién estamos juzgando?» publicado en CTXT el 16 de noviembre de 2017 nos sirven de marco para lo que tratamos de abordar a continuación: el análisis del discurso que los medios españoles han contribuido a construir y difundir sobre el denominado «Caso de La Manada». Este trabajo apunta aquellas subjetividades que han emergido en la construcción narrativa de este caso vinculadas a la cultura de la violación que permea la sociedad y al ejercicio de lo que Barjola denomina microfísica sexista del poder (2018) siguiendo de cerca los pasos de Foucault (1979).

Un discurso mediático en el que, pese a que se atisban buenas intenciones (qué peligrosas son a veces las buenas intenciones), se reproduce una ideología que abunda en estereotipos e imaginarios heteropatriarcales. Un relato que ha puesto el foco en la víctima, la superviviente, la denunciante, en lugar de centrarse en los hechos y en los agresores; en interpretar acudiendo a fuentes solventes, o en contextualizar y dar cuenta de otros casos de sentencias y juicios por abuso sexual. Un discurso que en bastantes momentos hace esfuerzos por emerger contrastado y respetuoso pero que en demasiadas ocasiones se desliza hacia la estigmatización y revictimización hasta reforzar el estado de desigualdad existente entre la forma de juzgar a las mujeres y a los hombres.

\section{Breve cronología del caso}

En este estudio nos detenemos en el análisis del discurso que difundieron los medios de comunicación españoles, prensa escrita y televisión principalmente, durante el mes de noviembre de 2017, cuando tuvo lugar el juicio oral por el denominado «Caso de La Manada» en la Audiencia Provincial de Navarra.

Los hechos juzgados se remontan a julio de 2016, a la madrugada del 7 de julio en Pamplona, durante las fiestas de San Fermín, cuando una mujer de 18 años denunció a cinco hombres por violación. Los cinco implicados se denominan a sí mismos en un grupo de Whatsapp «La Manada», de ahí el nombre con el que se conoce este caso. Este juicio concentró la atención del país y los medios se ocuparon con profusión de dar cuenta de lo que sucedía en la Audiencia. Un juicio que desencadenó manifestaciones feministas multitudinarias de apoyo a la denunciante, como la que tuvo lugar el 17 de noviembre de 2017. Un clamor de mujeres que apelaban por un juicio justo al grito unánime de «Hermana, yo sí te creo», al entender que se estaba poniendo en tela de juicio o sojuzgando el testimonio de violación múltiple de la denunciante. Este asunto de la «credibilidad» del testimonio, ligado a conceptos como el de «consentimiento» y el de «resistencia», han sido claves para el caso (Requena Aguilar, 2018). Es interesante además subrayar la dimensión colectiva que adquiere esta movilización: de multiplicidad de voces, que estructuran un discurso coral de denuncia frente a la 
barbarie, en medios, en redes, en el ámbito digital; pero también de multiplicidad de cuerpos que salen a las calles y que representan a ese «cuerpo público» abusado, agredido e intimidado que encarna la denunciante. Una comunidad con presencia física en los espacios públicos que se arma y configura como comunidad digital en las redes para promover cambios. Esta es la manera combinada (redes y plazas) de las nuevas formas de activismo y movilización. Nuevas estrategias de visibilidad y protesta que vienen aplicando muchos movimientos sociales en la actualidad, como \#Yosoy132, \#OccupyWallStreet, entre tantos otros.

Una fórmula parece que eficaz de denuncia en pleno siglo XXI (Reguillo, 2017). Las feministas mostraron su irritación frente al caso ese mes de noviembre de 2017, y en manifestaciones y convocatorias posteriores durante el 2018. En España, consignas como «aquí está tu manada» en apoyo a la víctima se escucharon por todo el territorio. Y es relevante esta actitud grupal y la creación de esta comunidad o sororidad, por muchos motivos: uno fundamental, la fuerza que tiene la masa frente al individuo; y otro estructural, la denuncia de la denominada disciplina del terror sexual por Barjola (2018) en su minucioso estudio sobre el conocido caso de «las niñas de Alcasser» de 1993. Una disciplina que se ejerce sobre el cuerpo femenino. Existe un discurso sobre un «mal esencial» e inevitable, una agresión sexual reiterada, para nada excepcional, sino repetida e incluso identitaria, que se concreta en detalles morbosos específicos, y que afianza la idea del «cuerpo dócil» femenino. Una mujer debe cuidarse (disciplinarse) para evitar el daño que puede producirse en el espacio público (y no sólo) si vuelve sola a casa por la noche, si sale de fiesta y va a discotecas, si bebe alcohol, si lleva minifalda o mallas ajustadas. Esta información refuerza la disciplina del terror sexual que aúna «el miedo al castigo físico y el autocontrol de riesgos, como mecanismos aprendidos e interiorizados en las prácticas cotidianas de las mujeres» (Barjola: 2018, 137-138).

Hay que tener presente para este caso que hacía tan solo un mes, en octubre de 2017, había estallado en Estados Unidos, a raíz del caso de denuncias de acoso sexual sobre el empresario hollywodiense, Harvey Weinstein, la campaña contra el abuso sexual \#metoo que ha tenido enorme repercusión en el resto del mundo. Un ejemplo más de paisaje insurrecto para emplear la terminología de Reguillo (2017). El contexto ideológico y político daba para que el caso de «La Manada» se convirtiese en epítome de la reivindicación feminista contra el abuso sexual en España. De hecho, el éxito de la jornada de huelga y manifestación del 8 de marzo de 2018 sin duda está ligado al caso de indignación y reivindicación colectiva feminista que abordamos.

Y si el juicio fue mediático y levantó polémica, no lo fue menos la sentencia que se dictó el 26 de abril de 2018. La Audiencia Provincial de Navarra condenó a «La Manada» por un delito continuado de abuso sexual a nueve años de prisión. De abuso sexual pero no de agresión sexual, ni tampoco fueron condenados por el delito de intimidación. El tribunal entendió que no existió violencia e intimidación, aunque sí consideró que hubo prevalimiento, que se produce cuando el agresor se aprovecha de una situación de superioridad con respecto a la víctima. Ante esta sentencia, surgieron nuevas manifestaciones al día siguiente por toda España al grito unánime de «No es no». Tal fue la repercusión que el Ministro de Justicia en ese momento, Rafael Catalá, llegó a plantear una posible 
revisión del Código Penal ante la duda de si los delitos sexuales estaban bien tipificados en el mismo. El relato judicial puesto en entredicho, en duda, no ya por las feministas, sino por el Ministro de Justicia del Partido Popular. Como se recoge en elmundo.es, una parte importante de la clase política mostró su desacuerdo con la sentencia:

Pedro Sánchez, entonces en la oposición, fue así de contundente en su Twitter: «Ella dijo NO. Te creímos y te seguimos creyendo. Si lo que hizo \#LaManada no fue violencia en grupo contra una mujer indefensa, ¿qué entendemos entonces por violación?». Aún más explícito fue Pablo Iglesias: «¿Cómo que no hubo intimidación? Parece que se estuviera diciendo a las víctimas que si no te enfrentas a cinco matones que te doblan en tamaño, arriesgando la vida, no te están violando. Vergüenza y asco».

Las críticas llegaron de todas las formaciones. "Como ciudadano y como padre me cuesta asumir la sentencia de \#LaManada», dijo Albert Rivera. «Siento un profundo rechazo hacia la sentencia de La Manada porque \#NOesNO», manifestó el popular Javier Maroto (Ortíz, 8 de noviembre de 2018).

En la plataforma change.org se abrió una campaña que solicitaba al Supremo la «inhabilitación de los magistrados encargados de dictar sentencia en el juicio de La Manada», petición que aún está activa y que cuenta con 1.444.000 firmas de apoyo. Un discurso hegemónico, el judicial, cuestionado en la actualidad como tantos otros discursos presentados como universalistas y totalizadores desde todo ámbito: ideológico, financiero, identitario, histórico... (Lyotard, 1987). Metarrelatos que ya no responden ni representan a la ciudadanía desde hace demasiado tiempo por lo que quedan en entredicho de manera reiterada.

Y la indignación social continúa y se acrecienta con este caso cuando el 21 de junio de 2018 la Audiencia de Navarra pone en libertad provisional a «La Manada» bajo fianza de 6.000 euros. Llevaban en prisión preventiva dos años. El 27 de junio la denunciante escribe una carta que envía a Tele5 a «El programa de Ana Rosa» (Quintana) que la propia presentadora leyó en directo. En este escrito daba las gracias por el apoyo recibido de familiares, amigos y anónimos durante los dos años que lleva este proceso y animaba a contar, a denunciar a aquellos que hayan pasado por situaciones semejantes. El 18 de julio la Audiencia de Navarra desestimó los recursos presentados por la acusación contra la libertad provisional de los cinco miembros de «La Manada». Sin embargo, el 2 de agosto de 2018, Ángel Boza, uno de los miembros del «La Manada», ingresa de nuevo en prisión acusado de robo con violencia, tras haber sido arrestado por robar unas gafas de sol en El Corte Inglés del centro de Sevilla y darse a la fuga en coche, lesionando a dos vigilantes de seguridad. Transcurrido el verano, el 25 de octubre de 2018, otro de los miembros de «La Manada», Alfonso Jesús Cabezuelo Entrena, soldado del Ejército de Tierra, es expulsado de las Fuerzas Armadas. Aún queda tiempo para una sentencia en firme. Se sigue a la espera de la una última resolución. El Tribunal Superior de Justicia de Navarra decidió el 7 de noviembre de 2018 sobre los recursos que todas las partes presentaron a la polémica sentencia del mes de abril, aunque el fallo no se dará oficialmente a conocer a los letrados y a la opinión pública hasta dentro de un mes. Se entiende que a finales de 2018 habrá sentencia firme. 


\section{El discurso de los medios: subjetividades emergentes}

La mayoría de los medios nacionales han optado por reproducir de manera literal las declaraciones que iban dándose en el juicio que tuvo lugar en noviembre en la Audiencia Provincial de Pamplona. En ocasiones hasta se han publicado completas, como hizo El Mundo. Esta práctica digamos que exime al periodista de manipulación alguna y es lo que compete. Sin embargo, un error frecuente, que han sabido detectar desde el Observatori Regular per la Igualtat de Géner en Noticiaris (Origen), consiste en difundir de manera acrítica declaraciones de los agresores sin contrastar ni contextualizar. Convirtiéndose así el medio en portavoz o vocero de los encausados. En el «Apunte 36» del Observatori se analiza una noticia del informativo de la Sexta 2 que reproduce un relato exculpatorio de uno de los encausados sin aportar más información, por lo que difunde aseveraciones que niegan la versión de la mujer agredida sin contrastarlas. «La pieza analizada recoge diversos fragmentos de la carta que él escribe desde la cárcel a la mujer, en la que le reclama acabar con «el sufrimiento inmerecido de cinco familias [...] completamente destrozadas por una mentira que, según él, dijo «para salir del paso».

Por otro lado, y como es habitual en estos casos, en muchas ocasiones estas declaraciones se recortan. Solo se seleccionan aquellas frases que se entienden como especialmente relevantes. Ahí subyace la interpretación. Y son estos recortes los que terminan por generar distorsiones cognitivas que han abundado principalmente en una victimización secundaria. Las declaraciones de letrados como Agustín Martínez Becerra, abogado defensor de cuatro miembros de «La Manada», recogidas hasta la saciedad por los medios, han servido para sojuzgar y desacreditar la versión, la actuación y hasta el supuesto carácter de la víctima, como denunciaron muchas protestas feministas en las calles de diversas ciudades. Dos cuestiones fueron resaltadas y explicadas de manera correlativa por este personaje, que ha funcionado a la manera de Jacques Vergès, y salvando las distancias, como reencarnación del «abogado del diablo»: se trata de una «relación sexual consentida» y no de una violación porque ella no dijo que no, ni gritó, ni se resistió, como ponen de manifiesto, según su parecer, las imágenes que grabaron los agresores con su móvil y el hecho de que en la actualidad la «joven» (siempre ha sido «la joven», con «rictus juvenil», incluso, no una mujer con razón y un sujeto de pleno derecho, sino una joven sentimental, emotiva, que se nos muestra llorando en un banco) siga su vida de estudiante, se vaya de viaje, acuda a fiestas y cuelgue fotos en Facebook como la de la camiseta con el lema «Hagas lo que hagas, quítate las bragas». Y el subtexto perverso de esta caracterización emocional, de esta subjetividad, es decir, de una joven que no reconoce ni puede controlar bien sus emociones, viene a decirnos que no controla tampoco su sexualidad.

Revictimización que llegó a su apogeo cuando se supo que la declarante había sido vigilada por un detective privado para tratar de «aclarar» si su proceder respondía a la sintomatología «esperable», (quizá habría que decir «deseable» para muchos), de quien está pasando por un estrés postraumático. Es sintomático también lo omitido: que no haya surgido por ninguna parte un discurso de resiliencia con respecto a la declarante. Acostumbrados como estamos a discursos de superación, que se aplauden 
desde todos los medios, ante esta realidad parecen no ser pertinentes. La violación es un punto ciego. Una mujer violada debe desaparecer, silenciarse o estar destrozada para que sea creíble.

Dos aspectos hicieron saltar todas las alarmas: ¿qué se entiende por una relación sexual consentida? y ¿cómo es posible que se vigilen los hábitos de vida de la denunciante con posterioridad a la sucesión de los hechos? Emergió con fuerza «la cultura de la violación». La violación, un delito por el que la víctima se ve obligada a demostrar su inocencia. Algunos medios recogieron opiniones valiosas como la de Laura Freixas (2017) en La Vanguardia, la de Lidia Falcón (2017) en Público, la de Luz Sánchez-Mellado (2017, 2018a, 2018b) en El País, o la de Isabel San Sebastián (2017) en ABC. Luz Sánchez-Mellado se ha ocupado y preocupado de un modo muy concreto por poner de manifiesto el valor de la denunciante y de denunciar el fariseísmo de una parte importante de la sociedad y del sistema judicial:

La duda que me corroe es qué les digo esta noche a mis hijas: una rayando la mayoría de edad y la otra recién cruzada esa delicadísima línea. ¿Que si denuncias a un sujeto que te ha penetrado por todos tus orificios sin tu consentimiento pero sin ponerte un cuchillo en el cuello ni amenazarte con matarte, no te ha violado sino solo abusado de tu cuerpo? ¿Que eso dice el Código Penal y que la sentencia es impecable porque así están las cosas? ¿Que, puestas en el caso, se dejen hacer para evitar males mayores, o que se resistan como vírgenes mártires para demostrar que ellas no querían? ¿Que no se metan solas en un portal con cinco hombres? (Sánchez-Mellado, 13 de noviembre de 2018a: web).

Como es habitual en el tratamiento de los «sucesos», lo primero ha sido dar forma a unos personajes que vienen a reforzar los estereotipos y los prejuicios sociales. El discurso de los abogados defensores y la declaración de los agresores han dado lugar a atribuciones erróneas sobre la declarante al tratar en todo momento de aportar supuestos elementos causales «objetivos» como los comentados por el letrado Agustín Martínez Becerra. Y entre estos argumentos, el fundamental ha consistido en atribuir a la víctima una conducta provocadora (sus gestos, su actitud, el andar de fiesta por la noche y sola... en la calle). Existe una violencia patriarcal estructural pero se buscan indicadores individuales que puedan explicar lo sucedido. Una violencia de la que se responsabiliza a la mujer porque sucede en los peores escenarios posibles. Una vez más el espacio público se presenta como un lugar inhóspito para la mujer, que debería permanecer en el espacio doméstico e íntimo para que no le pase nada; pero tampoco porque la violencia sexual se da demasiadas veces en la casa, en el entorno familiar. «Si no hubiera ido por esa calle, si no hubiera sonreído, si me hubiera ido antes, si no hubiera ido sola, etc., son pensamientos comunes o que se escuchan socialmente cuando las mujeres sufren violencia sexual» (Monroy Romero, 2012: 50).

La calle, en cambio, es el espacio reservado al hombre, que por instinto y naturaleza es violento e incontrolable sexualmente. Y esto hay que disculparlo, qué le vamos a hacer, son así, y por eso es mejor que la mujer no ande suelta por ahí. Códigos culturales con los que se interpreta la realidad desde una perspectiva sexista que refuerza un imaginario «donde no hemos conseguido resignificar la conceptualización de las mujeres que no pase por personas vulnerables además de victimarias, y a los varones como víctimas de los comportamientos femeninos y/o de una biología que les impulsa a violentar a las mujeres» (Monroy Romero, 2012:48). 


\subsection{La cultura de la violación}

Estos comentarios sirven para ratificar un falso consenso social «no es de extrañar que algunas mujeres sean violadas» y otro aún más perverso que ya denunció Virgine Despentes en Teoría King Kong: «Imposible violar a una mujer tan viciosa» (2007: 29-46). Puede parecer exageración pero no lo es como pone de manifiesto El Daily Stormer, una web fascista (así se definen) hermana de la estadounidense The Daily Stormer. En un artículo infamante en el que se van haciendo apostillas a las declaraciones de la denunciante del caso de La Manada conocidas por la sentencia, se hacen concretamente estos dos comentarios que redundan en lo que se viene señalando: «¿Qué busca una mujer con leggins y tanga en los sanfermines?» $\mathrm{y}$ «Y aun suponiendo que hubiera sido forzado, ¿desde cuándo puede uno violar a una puta?» (González, 2018a, web).

En esta web se publicaron fotos de la denunciante y se difundieron datos sobre su identidad. En diferentes artículos o entradas se la increpa de diversas formas, con comentarios a su vez divulgados por el conocido portal ForoCoches. En concreto, la comunidad blanca, machista y heteropatriarcal de la que se erige como representante El Daily Stormer con comentarios como: «España ha dejado de ser un Estado de derecho, no existe ninguna seguridad jurídica para el hombre español heterosexual» (González, 2018b), se siente amenazada por los nuevos tiempos. Las formas de estar y de socialización de muchas mujeres de hoy en día inquietan a esta «comunidad». De manera particular se refieren, en diversos artículos dedicados al caso de La Manada, a un sector femenino que denominan «femimarxistas», porque el término «feminazi», con el que son descalificados algunos sectores feministas en otros ámbitos, supondría un halago para esta web, en cambio, el marxismo y el feminismo son los causantes de los «desatinos» que afectan a las mujeres en la actualidad. En estos artículos podemos encontrar comentarios como:

No existen mujeres rebeldes, solo mujeres haciendo lo que creen que puede aportarles mayor aprobación social. La mujer española es hoy femimarxista no por propia iniciativa, sino porque es lo que quiere el Régimen globalista imperante, interesado en una guerra de sexos para destruir el pilar del Estado nacionalista -la familia-, la cohesión social, y arruinar la natalidad -en el marco del reemplazo étnico-. Os reto a buscar una sola organización femimarxista mínimamente relevante que no esté subvencionada por el Gobierno español, la UE o el propio Soros.

El movimiento femimarxista, financiado y auspiciado por las élites patriarcales que locas del coño y hombres beta dicen querer combatir, se extiende por todo Occidente. En España, sin embargo, me atrevo a decir que somos los campeones a nivel mundial. El odio y la división que se ha conseguido sembrar aquí entre hombres y mujeres es digno de estudio. El femimarxismo ha conseguido obligar a nuestras mujeres a dedicar sus años de mayor fertilidad al estudio de carreras que no necesitan; luego, les quitan el trabajo a hombres que, como consecuencia, se ven obligados a renunciar a formar una familia. Las mujeres que se quedan embarazadas, abortan. Los pocos hombres que se casan, se divorcian, en el mejor de los casos. En el peor, privados de toda presunción de inocencia, acaban entre rejas por una denuncia falsa, para luego vivir en casa de sus padres, mientras pasan una pensión alimenticia a sus ex, que viven en el piso pagado por ellos, con un nuevo maromo, y la custodia exclusiva de los hijos. De uno u otro modo, aquí nadie tiene hijos.

Los miembros de la Manada han sido condenados por la prensa y la muchedumbre femimarxista antes de iniciarse siquiera el juicio. A pesar de la enorme presión mediática y política, han sido absueltos de violación. Han sido condenados, sin embargo, por abuso sexual. Hasta que no sean absueltos, España no es un Estado de derecho (González, 2018b).

Es claro que El Daily Stormer, ForoCoches o Burbuja son casos extremos pero no hacen sino exacerbar ciertos estados de pensamiento sexistas, profundamente machistas, que evidencian la 
existencia de una suerte de «saber», «de verdad», que se produce y reproduce casi de modo inmanente en la estructura social. Lo burdo de estos comentarios nos resulta fácil de reconocer pero la mecánica suele ser mucho más sibilina. La microfísica sexista del poder se sostiene a toda costa (Barjola, 2018). El individuo que sabe que tiene un privilegio, el que sea, para este caso los hombres frente a las mujeres, desde una construcción binaria rentable y dentro de un sistema patriarcal, mantendrá esa ventaja como sea necesario, con violencia si es el caso, de ahí que este ejercicio del poder se perpetúe y sea infalible.

\subsection{Caperucita y los lobos}

Y si bien la mayoría de las acusaciones han venido de parte del sistema judicial, los medios de comunicación, en un intento por apoyar a la víctima han optado por construir un sujeto femenino «infantilizado», ingenuo, sentimental, no racional, y caracterizado, como suele pasar con las mujeres, por la relación familiar, en tanto que hija o hermana.

Comentarios maternales como los de Isabel San Sebastián en su columna «En manada» en $A B C$ lo evidencian:

¡Podría haber sido mi hija o la de cualquiera de ustedes! Una chica de dieciocho años que acude a unas fiestas en las que reina el alcohol, se pasa con las copas (o con lo que quiera que tomase, es completamente irrelevante a los efectos que nos ocupan) y se encuentra de pronto frente a frente con cinco hombres hechos y derechos que prácticamente le doblan la edad (2017);

y paternalistas y condescendientes como los de Andros Lozano en «Querida chica de San Fermín: no te culpes yo sí te creo» en El Español:

\footnotetext{
Quizás, el pasaje más doloroso de tu relato es cuando, a preguntas de la fiscal, reconoces que hubo un momento en el que notaste sentimiento de culpa por haber puesto la denuncia, que tenías remordimientos por haberlo hecho. En tus palabras denotas la candidez e ingenuidad propias de una chica de tu edad, buena hija, buena estudiante...» (...) «No te martirices, por favor. Tú eres la víctima y ellos no merecen que te sientas culpable por nada. La Manada ni siquiera te ha pedido disculpas ni perdón hasta el momento. Y son ellos quienes se sientan en el banquillo de los acusados. Pronto dejarás de soportar las miradas inquisitorias de quienes dudan de tu palabra. Son pocos, muy pocos. Te lo garantizo, aunque hagan mucho ruido. Yo me pregunto si pensarían lo mismo si, en vez de tú, hubiera sido su hija, su hermana, su madre la que entró en aquel portal (2017a. Las cursivas son mías).
}

Ya desde el titular con «Querida chica» y la elección del formato de carta personal que le dirige el periodista a la víctima, que por joven mujer entiende que puede tutear como si la conociese de toda la vida, incluso, se apropia de la experiencia, que él puede comprender y explicar perfectamente. Y además «denotas la candidez e ingenuidad de una chica de tu edad, buena hija, buena estudiante» «no merecen que te sientas culpable», «si en vez de tú hubiera sido su hija, su hermana, su madre...»El empleo retórico de la negación, responder desmintiendo, no es verdad que..., solo contribuye a extender un presupuesto, a legitimar una supuesta opinión extendida. En definitiva, lo de siempre: la mujer definida como puta o como santa, y para el caso, como una «lolita» o como una niña ingenua. No salimos de ese constreñido binomio. Se trata de dejar de representar a las mujeres como objetos y de empezar a verlas como sujetos agentes frente a la violencia. Porque de otro modo lo único que se 
reproduce es la imagen de «víctimas pasivas, incapaces de resolver ninguna situación de agresión, puesto que responde a actos incontrolables que además son cometidos por seres fuera de sí, por lo que el ejercicio de prevención es prácticamente imposible» (Monroy Moreno, 2012: 50).

Pero aún nos falta un personaje fundamental en este relato: el monstruo. Lo irracional y animal que han venido a encarnar a la perfección los agresores que se denominan a sí mismos a través de ese grupo de WhatsApp como «La Manada». Una jauría de lobos, amparados en el grupo y alentados por un líder, «El Prenda». Una acción colectiva orgiástica que desplaza o elimina la culpa. El que no participe corre el peligro de ser contemplado con desconfianza y hasta desde la anormalidad por el resto del grupo. Posesión grupal que instala de nuevo el mito del centauro, incapaz de distinguir entre vida sexual y violencia sexual. Un éxtasis grupal perverso que Luigi Zoja (2018) en su estudio sobre los orígenes de la violencia masculina denomina: centaurismo. Una manada, un imaginario colectivo, que viene a representar a «los otros» y que se contrapone a un «nosotros», que minimiza la responsabilidad social y la de los agresores, como exponen en su trabajo «Dones valentes; per una nova información sobre les violències sexuals» la psicóloga Violeta García y la periodista Isabel Muntané (2016). El mal presentado como excepcional y no como síntoma de la ideología machista de la sociedad en la que habitamos. Si la violencia ejercida por «La Manada» se presenta como un hecho aislado, excepcional, parecería que la responsabilidad se diluye. Sin embargo, si se va un paso más allá, desde el reconocimiento del ejercicio de la microfisica sexista del poder, y se entiende que es precisamente esta excepcionalidad la que permite y subraya la norma: «el caso excepcional transparenta de la manera más luminosa la esencia de la autoridad» (Agamben, 2003: 28. Cito por Barjola, 2018:141). «La violencia sexual que cimienta la sociedad será la norma a la que la excepción protegerá y perpetuará» (Barjola, 2018: 141).

Y de otro lado, algunos medios escritos, y no digamos en programas televisivos como «Detrás de la verdad»o «Espejo público», en un exceso de celo por querer mostrarse ecuánimes y respetuosos con el caso que se estaba juzgando en los tribunales, han optado en ocasiones por mecanismos discursivos que ayudan en alguna medida a exculpar a los agresores al mostrar aspectos personales de los mismos y humanizarlos.

En el reportaje de Andros Lozano (2017b) en El Español, «La vida 'normal' de la chica violada en San Fermín: universidad, viajes y amigas» (titular desafortunado donde los haya), tras dar cuenta en primera instancia de cómo la víctima ha tratado de «normalizar su vida» en este casi año y medio previo al juicio, gracias a las declaraciones de una amiga íntima de ésta; acto seguido y en un mismo plano aduce:

Pero no sólo la vida de la víctima ha cambiado en estos casi 16 meses transcurridos. También la de los miembros de La Manada»: «Jesús Escudero ha perdido su empleo como peluquero; el soldado Alfonso Jesús Cabezuelo ha sido apartado de la Unidad Militar de Emergencia (UME) en la que trabajaba; Ángel Boza recibe «cabizbajo y deprimido» las visitas que sus familiares le hacen al penal de Pamplona, y José Ángel Prenda ha perdido una veintena de kilos y se ha centrado en el deporte. Pesas y carrera continua... Así mata el tiempo cuando sale al patio de la penitenciaría navarra. Cuando comparezca en sede judicial ya no será el chico grueso que se paseaba por Pamplona medio desnudo horas antes de la supuesta violación. Mientras, el amigo guardia civil de todos ellos, Antonio Manuel Guerrero Escudero, ha sido padre mientras pasa su vida entre rejas. Dejó embarazada a su pareja en un vis a vis en la prisión (2017b). 
El broche de oro de esta humanización sin duda lo puso de nuevo el abogado defensor en la lectura de sus conclusiones, que sirvieron de titular a tantos medios, al comentar que sus defendidos «no son modelo de nada» y que pueden parecer «imbéciles, patanes, infantiloides, simples y primarios, pero son buenos hijos y quieren a su familia» (Lozano, 2017b).

En resumen: la narrativa mediática para lo que hasta ahora se conoce del Caso de La Manada ha optado por construir un relato maniqueo, de cierto tono melodramático. Se han legitimado y difundido discursos estigmatizadores y se ha contribuido a perpetuar los estereotipos de género que se dieron en el juicio. La denominada disciplina del terror sexual se perpetúa en el relato de los jueces, en el relato de los medios. La microfísica sexista del poder sigue su curso aunque algo obstaculizada y, sobre todo, puesta en evidencia por las masivas movilizaciones feministas que han tenido lugar durante este 2018 en España.

\section{Referencias bibliográficas}

Agamben, Giorgio (2003). Homo sacer, el poder soberano y la nuda vida. Valencia. Pretextos.

BARJOLA, Nerea (2018). Microfísica sexista del poder. El caso Alcàsser y la construcción del terror sexual. Barcelona. Editorial Virus.

Despentes, Virgine (2007). Teoría King Kong. Barcelona. Melusina.

FALCón, Lidia (2017). «La violación, castigo para mujeres». Público. 19 de noviembre. Consultado el 13 de noviembre de 2018 en https://blogs.publico.es/lidia-falcon/2017/11/19/la-violacioncastigo-para-mujeres/

FoucAult, Michel (1979). Microfisica del poder. Madrid. Las Ediciones de La Piqueta.

FREIXAS, Laura (2017). «Cultura y violación». La Vanguardia. 30 de noviembre. Consultado el 14 de noviembre de 2018

https://www.lavanguardia.com/opinion/20171130/433299990538/cultura-y-violacion.html

GARCÍA, Violeta y MunTANÉ, Isabel (2016). Dones valentes; per una nova información sobre les violències sexuals. Barcelona. Màster Gènere i Comunicació.

GIMENO, Beatriz (2017). «¿A quién estamos juzgando?». Revista CTXT. 16 de noviembre. Consultado el 13 de noviembre de 2018 en https://ctxt.es/es/20171115/Firmas/16201/cultura-violacionjuicio-san-fermin-feminismo-beatriz-gimeno.htm

GONZÁlEZ, José (2018a). «Masturbar «por instinto»: las disparatadas declaraciones de Clara, la noviolada de los sanfermines». El Daily Stormer. 6 de mayo. Consultado el 14 de noviembre de 2018 en_https://es.dailystormer.name/2018/05/06/masturbar-por-instinto-las-disparatadasdeclaraciones-de-clara-la-no-violada-de-los-sanfermines/

GonZÁlez, José (2018b) «La «víctima» de la Manada es una gorda indeseable que denunció por despecho». El Daily Stormer. 4 de mayo. Consultado el 14 de noviembre de 2018 en 
https://es.dailystormer.name/2018/05/04/la-victima-de-la-manada-es-una-gorda-indeseableque-denuncio-por-despecho/

LozAno, Andros (2017a). «Querida chica de San Fermín: no te culpes yo sí te creo». El Español. 7 de diciembre. Consultado el 14 de noviembre de 2018 en https://www.elespanol.com/reportajes/20171206/267593239_12.html

LozANO, Andros (2017b). «La vida "normal" de la chica violada en San Fermín: universidad, viajes y amigas». El Español. 9 de noviembre. Consultado el 14 de noviembre de 2018 en https://www.elespanol.com/reportajes/20171111/261224141 $0 . \mathrm{html}$

LyotARD, Jean Francois (1987). La condición posmoderna: informe sobre el saber. Buenos Aires. Cátedra.

MoNROY MORENO, Maitena (2012). «Terror sexual y control de las mujeres versus caperucita roja se come al lobo». En Violencias machistas y estrategias para enfrentarlas. Bilbao. Mugarik Gabe. (47-59).

OBSERVATORI regular per la igualtat de géner en noticiaris (ORIGEN). Consultado el 13 de Noviembre de 2018 en http://observatoriorigen.org/apuntes/?lang=es

ORTíz, Ana María (2018). «Pendientes del fallo de La Manada». Elmundo.es. 8 de noviembre. Consultado el 14 de noviembre de 2018 en https://www.elmundo.es/espana/2018/11/08/5be33de6ca4741231f8b4608.html

REguilLo, Rossana (2017). Paisajes insurrectos. Jóvenes, redes y revueltas en el otoño civilizatorio. Barcelona. NED ediciones.

ReQuena AGUILAR, Ana (2018). «los conceptos clave de la sentencia de 'La manada': de la credibilidad al consentimiento y la intimidación». Eldiario.es. 28 de abril. Consultado el 13 de noviembre de 2018 en https://www.eldiario.es/sociedad/palabras-sentencia-credibilidadconsentimiento-intimidacion $0765374348 . \mathrm{html}$

_ (2018a). «¿Qué les digo a mis hijas?». El País. 27 de abril. Consultado el 13 de noviembre de 2018 en https://elpais.com/politica/2018/04/26/actualidad/1524764447 943505.html

_ (2018b). «A la víctima». El País. 28 de junio. Consultado el 13 de noviembre de 2018 en https://elpais.com/elpais/2018/06/27/opinion/1530117209 739226.html

SAN SEBAStiÁN, Isabel (2017). «En Manada». Abc. 27 de noviembre. Consultado el 14 de noviembre de 2018 en https://www.abc.es/opinion/abci-manada-201711270450 noticia.html

SÁNCHEZ Mellado, Luz (2017). «Por puta». El País. 16 de noviembre. Consultado el 13 de noviembre de 2018 en https://elpais.com/elpais/2017/11/15/opinion/1510768873 516497.html

SenTENCIA por el caso de «La Manada» en elplural.com consultado el 13 de noviembre de 2018 en https://www.elplural.com/sociedad/documento-lee-aqui-la-sentencia-completa-de-lamanada 126896102

ZojA, Luigi (2018). Los centauros. En los orígenes de la violencia masculina. Buenos Aires. Fondo de Cultura Económica de Argentina. 